ARCHIVOS

de historia del movimiento obrero y la izquierda
ISSN 2313-9749

ISSN en línea 2683-9601

Año X, no 19, pp. 21-41

septiembre de 2021-febrero de 2022

\title{
Primavera, invierno, primavera. Los ciclos de luchas feministas y la izquierda uruguaya
}

\author{
Ana Laura de Giorgi \\ Universidad de la República, Uruguay \\ analauradegiorgi@gmail.com \\ ORCID: 0000-0002-4304-6514
}

Título: Spring, winter, spring. The feminist struggle cycles and the Uruguayan left wing

Resumen: La relación entre la izquierda y el feminismo ha sido de encuentros y desencuentros. Este diálogo entrecortado también ha impactado en los estudios sobre uno y otro proyecto emancipatorio. Los estudios sobre la izquierda se han centrado en múltiples aspectos pero prácticamente no han considerado las ideas y prácticas feministas que emergieron en el seno de la izquierda. Por su parte, los estudios sobre los feminismos han tomado la misma distancia: se han estudiado organizaciones e ideas como si no tuvieran vínculo alguno con la izquierda. Este artículo tiene como principal objetivo comprender al feminismo en esa relación, analizando el caso uruguayo donde resulta imprescindible considerar ambos proyectos de forma conjunta, principalmente para los 80 , pero también en la actualidad.

Palabras clave: feminismo - izquierda - ciclos feministas - Uruguay

Abstract: The relationship between left and feminism has been one of encounters and misencounters. This uneasy dialogue has also impacted on studies on both projects. Studies of the left have focused on multiple aspects but have

DOI: https://doi.org/10.46688/ahmoi.n19.327

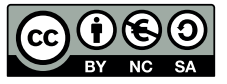

Obra bajo licencia Creative Commons 4.0 International (Atribución - NoComercial - Compartirlgual) 
hardly considered the feminist ideas and practices that emerged within the left. Studies on feminisms have taken the same distance: organizations and ideas have been studied as independent of the left. The main objective of this article is to understand feminism in this relationship, analyzing the Uruguayan case where it is essential to consider both projects together, mainly for the eighties, but also today.

Keywords: feminism - left wing - feminists cycles - Uruguay

Recepción: 6 de julio de 2021. Aceptación: 10 de agosto de 2021

$* * *$

\section{Introducción}

Durante los 70 y 80 en América Latina emergió un movimiento feminista habitado en gran parte por aquellas mujeres que provenían de la izquierda, que mantenian su preocupación por la desigualdad de clase, pero que centraron energías en denunciar y revertir la desigualdad de género. En Uruguay, este contingente de feministas autodenominadas "de izquierda" fue el protagonista del período posdictadura y, aunque reconfigurándose en sus espacios de circulación y modos de intervención, es uno de los principales desafíos para la izquierda uruguaya hasta la actualidad.

Este texto busca reconstruir una larga historia de encuentros y desencuentros entre el feminismo y la izquierda en Uruguay. Una relación que no ha sido acompañada por las investigaciones realizadas sobre los $80, \operatorname{los} 90$, los 2000, sobre la izquierda o sobre el feminismo. La historia política y la ciencia política se han detenido en grandes eventos históricos o en los actores protagonistas, como sucedió con la década del 80 en la que prima una visión anclada fundamentalmente en la negociación entre elites politicas y militares. Algunos estudios críticos de las miradas clásicas de la transitología permitieron visibilizar las disputas de sentido sobre la democracia y la política (Lesgart, 2003; Rico, 2005) y aunque seguramente lo sospecharon, no se detuvieron a analizar el rol del feminismo en dicho proceso.

Con respecto a las investigaciones que refieren a la izquierda uruguaya luego de la dictadura, el campo de la historia prácticamente no ha producido estudios sobre este período. Por su parte, otras investigaciones se han concentrado fundamentalmente en la trayectoria politica del Frente Amplio (FA) y en las adaptaciones de esta coalición a las reglas de la competencia electoral (Garcé y Yaffé, 2005; Yaffé, 2005).

Estas permiten comprender la redefinición de estrategias politico-electorales y el paulatino corrimiento hacia el centro en el espectro 
ideológico en el marco de la competencia electoral bajo el lema FA. Sin embargo, han prestado poca atención a los procesos de discusión interna sobre otros asuntos más allá de la estrategia electoral y de la agenda del "cambio estructural". La reconstrucción sobre el debate respecto a los sentidos de la izquierda ha quedado pendiente, justamente cuando para varios actores dentro del campo de la izquierda resulta imprescindible incorporar nuevas ideas como la de los derechos humanos o la igualdad de género.

Lo que Karin Grammático (2005) señala para los 70, respecto de la no consideración del feminismo argentino como parte de las propuestas de cambio social, puede señalarse también para los 80 en Uruguay y además extenderse en el tiempo. Si el feminismo no es considerado como parte de la discusión política de la izquierda, rápidamente puede ser concebido como un fenómeno de despolitización que anuncia la llegada del neoliberalismo y el posmodernismo. Analizar los aportes del feminismo de izquierda implica cuestionar justamente esta última mirada.

Algunos aportes sobre los estudios históricos del feminismo arrojan pistas sobre esa relación, aunque no ha sido el foco de atención. Algunos trabajos analizan trayectorias de las militantes feministas y señalan la llegada al feminismo desde la izquierda (Pedro, 2010). El trabajo de Costa (1988) sobre las feministas brasileñas señala cómo el despliegue de aquellas ideas y la organización en grupos de reflexión pudieron concretarse desde un feminismo "bien comportado" que, en el contexto de la dictadura, la izquierda no consideró amenazante.

Trabajos como los de Grammático (2005) y Trebisacce (2010, 2011, 2013a, 2013b), sobre el feminismo argentino son antecedentes significativos para analizar la relación entre izquierda y feminismo. Esta literatura es una referencia además para considerar los espacios sociales y partidarios del feminismo no como entidades absolutamente separadas $\mathrm{y}$ a las feministas que transitan entre ambos como sujetos con agencia que deciden por aquella estrategia y no como mujeres instrumentalizadas por los partidos políticos.

Parece indudable que el feminismo ha quedado fuera de la historia politica reciente local y al margen de los estudios de la izquierda. También que la relación con la izquierda desde los estudios feministas siempre ha sido un tema latente. Resulta entonces necesario analizar el feminismo inscripto en el campo de la izquierda y visibilizar las iniciativas feministas como parte del proceso de discusión de la propia izquierda. Este artículo realiza un largo recorrido buscando reconstruir los distintos momentos feministas de la izquierda y las interpelaciones mutuas a lo largo de cuatro décadas en Uruguay. 


\section{Primavera democrática}

La transición democrática durante la década del 80 fue el momento de emergencia del feminismo en el Uruguay, dado que, a diferencia de los países vecinos, casi no se contaba con antecedentes en la etapa previa a la dictadura. Similar a lo sucedido en otros países de la región (Feliú, 2009; Pedro, 2010; Pieper, 2010; Richard, 2001), el feminismo fue surgiendo en el marco de un amplio movimiento de mujeres que integraba el llamado "bloque opositor" a la dictadura cuyo principal propósito era la derrota del terrorismo de Estado. La invocación del feminismo fue una apuesta principalmente de las mujeres que pertenecian a la izquierda frenteamplista o tenian vínculos cercanos con ella. ${ }^{1}$ Las principales organizaciones sociales feministas que se transformaron en referencia mantuvieron estrechos vínculos con la izquierda, sus referentes eran dobles militantes y no integraron en sus filas a ninguna feminista de los partidos tradicionales.

Las dos organizaciones sociales feministas principales fueron el Grupo de Estudios sobre la condición de la mujer en Uruguay (Grecmu) y Cotidiano. Ambas fungieron como espacios de encuentro y formación para las feministas de la época y editaron las dos publicaciones feministas insignias como fueron La Cacerola y Cotidiano. Las dos eran organizaciones sociales, pero con fuertes vínculos con la izquierda uruguaya. En Grecmu, su fundadora Suzana Prates no participaba

1. En Uruguay, el término izquierda incluye a las organizaciones que confluyeron en el Frente Amplio fundado en 1971, una coalición de ideas y tradiciones que ha logrado construir una identidad propia y que desde sus inicios reunió a cristianos, socialistas, comunistas, trotskistas y grupos de centro escindidos de los partidos tradicionales. El Frente Amplio de la posdictadura se reconstituyó con los mismos grupos fundadores que habian logrado sobrevivir (Partido Socialista, Partido Comunista del Uruguay, Partido Demócrata Cristiano), con los que se rearticularon bajo nuevas denominaciones (como el Partido Socialista de los Trabajadores antes PRT) y con nuevas agrupaciones que se integraron como el Partido por la Victoria del Pueblo de tradición anarquista y el Movimiento Nacional de Liberación - Tupamaros (MLN-T). Aunque el FA ha tenido escisiones, principalmente la de 1989, y han surgido nuevas agrupaciones políticas que se definen como de izquierda, el Frente Amplio ha continuado incorporando nuevos grupos y es la principal fuerza politica de izquierda. En las últimas elecciones de 2019, partidos que podrian considerarse a la izquierda del FA como Asamblea Popular o el Partido de los Trabajadores, obtuvieron 19.700 votos y 1.300 respectivamente, frente al casi millón de votos del FA. La opción de centro producto de la escisión de 1989 alcanzó nada más que 20.500 votos. Es decir que desde su fundación la izquierda uruguaya se reúne bajo el lema Frente Amplio, no quedando opciones competitivas de izquierda fuera del FA y por eso los términos izquierda y Frente Amplio suelen abordarse como expresiones de un mismo fenómeno político. 
politicamente en los espacios partidarios pero brindaba continuamente talleres en el Frente Amplio. También lo hacían dos importantes figuras como Graciela Sapriza, que participaba en la Comisión de Mujeres del FA, y Silvia Rodríguez Villamil, quien además del FA fue fundadora de la Comisión de Mujeres del Partido Comunista. En Cotidiano un número muy importante de dobles militantes, en su mayoria del Partido por la Victoria del Pueblo pero también del Partido Comunista, lideraban la novel organización feminista.

A su vez, en las organizaciones partidarias que integraban el Frente Amplio se conformaron grupos de mujeres a partir de la iniciativa de feministas con amplia circulación por las organizaciones sociales. En el Partido Comunista se conformó hacia 1986 una Comisión de Mujeres integrada por quienes se autodenominaron "feministas" e integraban organizaciones sociales. Además de la Comisión de Mujeres del PCU, que fue la más visible, se conformó el grupo de mujeres del Partido Socialista (PS), el del Partido por la Victoria del Pueblo (PVP) y el del Partido Socialista de los Trabajadores (PST), junto a figuras importantes como la de Puyesky, del Partido por el Gobierno del Pueblo (PGP), y Margarita Percovich, de la Izquierda Democrática Independiente (IDI) y luego Vertiente Artiguista (VA). Todos estos grupos de las izquierdas conformaron la comisión general de mujeres del Frente Amplio. Ninguna de las feministas que impulsaron espacios orgánicos de mujeres participaron exclusivamente de ellos, sino que todas ejercieron de un modo u otro la doble militancia.

El feminismo de izquierda incluyó a personas con pertenencia a estructuras partidarias y a organizaciones sociales feministas. Como ellas recuerdan se conformó un "enjambre de abejas" que circulaban entre un espacio y otro y que realizaron un enorme esfuerzo por articular izquierda y feminismo. Un feminismo que se presentó como refundacional y tomó distancia de las vertientes "liberales" o "reformistas", términos utilizados tanto para denominar a las iniciativas de principios de siglo como las desplegadas por el gobierno de turno del Partido Colorado. Así emergió un feminismo que se autodenominó "de izquierda", "socialista" o "revolucionario" con una gramática propia delimitada por la cercanía con la politica partidaria, especialmente con la izquierda.

Una de las primeras movilizaciones masivas de mujeres en el Uruguay de los 80 , titulada justamente "las mujeres van de frente", fue liderada por las feministas frenteamplistas para hacer visible una nueva agenda de demandas en torno a las primeras elecciones de 1984. Esta movilización convocó a unas 100.000 mujeres y tuvo un alto impacto en la prensa ocupando la portada de varios diarios y semanarios. Era la primera vez que una manifestación de mujeres convocaba a un número tan alto de manifestantes. Fue una marcha de mujeres, pero también 
vale recalcar que fue una marcha de mujeres del Frente Amplio, no de todas las mujeres, y así la primera gran movilización masiva de mujeres en el Uruguay se desplegó con los colores rojo, azul y blanco.

Esta movilización no sólo demostró el contingente feminista, sino los limites que la fuerza política en la que muchas habitaban o simpatizaban imponía, ya que una de las medidas propuestas para aquella campaña electoral fue prohibida, aquella que solicitaba "democracia en el hogar". Específicamente se consignaba: "Lucha contra el autoritarismo en todos los frentes: democracia en el hogar. Tareas domésticas compartidas entre TODOS los miembros de la familia que estén en condiciones de realizarlas, independientemente de su sexo" (Informe de la Sub comisión de Programa sobre la condición de la mujer del FA, 1985). Esta medida fue rechazada por el Comando Electoral de la fuerza politica alegando que podría considerarse una invasión de la privacidad de los hogares.

La discusión sobre la opresión de género se dio en el marco de la dicotomía democracia-autoritarismo que delineó gran parte de los debates políticos de la época (Lesgart, 2003). La discusión sobre los autoritarismos permitió avanzar y visibilizar otros autoritarismos, como los ejercidos en el espacio doméstico. La chilena Julieta Kirkwood, ampliamente leída en el Uruguay, señaló explícitamente cómo la "experiencia cotidiana concreta de las mujeres es el autoritarismo" (Kirkwood,1984, p. 7). En un texto emblemático, de la misma autora, El feminismo como negación del autoritarismo (1983), Kirkwood señaló cómo el autoritarismo de las dictaduras se había sostenido en un autoritarismo social, que tampoco la izquierda había logrado contestar.

La politización de lo personal fue sin dudas una apuesta de este feminismo que tenía su propia versión de "lo personal es político" con la consigna "democracia en la casa". Aquí se buscaba discutir el estatus político de lo doméstico y al mismo tiempo visibilizar las injusticias políticas que alli se cometían. El autoritarismo denunciado tenía que ver con una desigual distribución de la carga de tareas domésticas fundamentalmente bajo lo que se señaló como "división sexual del trabajo" o "trabajo invisible".

El feminismo de izquierda, principal vertiente feminista de los 80 , comprendió la desigualdad de género desde el fenómeno del trabajo, ampliando los sentidos del trabajo y comprendiendo todas aquellas tareas no asalariadas imprescindibles también para la reproducción del capital. Así la comprensión de la opresión de género partía del corazón del marxismo, del fenómeno del trabajo (no del deseo o las identidades), pero tenía como principal objetivo señalar los vacíos dejados por el marxismo, perspectiva que se había "detenido en la puerta del hogar". ${ }^{2}$

2. De Barbieri, Fem, vol. 4, nº 17, 1981, p. 7. 
Esta no fue una mera sublevación con respecto al trabajo reproductivo -que puso en evidencia su centralidad, como en la actualidad señala Federici (2014, p.102)-, sino que se realizó un esfuerzo intelectual más que importante por explicar tempranamente la funcionalidad del trabajo invisible para la economía capitalista. Investigadoras, sociólogas, historiadoras inauguraron toda una corriente de investigaciones para demostrar este fenómeno, mientras que desde las revistas feministas se ensayó la divulgación de estas ideas con el objetivo de contestar la idea de naturaleza de ciertas tareas de cuidado.

Esta lectura de la opresión de la mujer en una clave marxista que impulsaron las feministas en Uruguay permitió comprender las funcionalidades del "trabajo reproductivo", pero siempre desde un esquema en el que la mujer fue visualizada como madre y esposa, y desde un esquema en el que la heterosexualidad apareció casi como natural. La opresión era concebida como la desigual distribución del trabajo reproductivo y las expectativas, puestas en los compañeros, lo que sin dudas supuso regulaciones y autorregulaciones constantes.

Las feministas de izquierda en aquellos tiempos desplegaron una fuerte crítica al orden de género y realizaron un llamado específico a los hombres, especialmente a los compañeros -políticos y afectivos-, aquellos que habían decidido "sacar a las mujeres de la cocina para hacer la revolución y luego las habian devuelto de la revolución a la cocina”. ${ }^{3}$ Durante los primeros años de la recomposición democrática el clima político de altas expectativas no instó a realizar grandes impugnaciones. Las nuevas formas de hacer politica debian convivir armoniosamente con aquellas viejas y, además, también existian expectativas sobre las posibles transformaciones de estas últimas. Desde el Partido Comunista surgió una nueva consigna: la del "partido habitable", que dio cuenta explícitamente de la necesidad de revisar algunos mandatos militantes. La idea de que la izquierda debía ser habitable se hizo extensiva a otros espacios y la nueva politica del feminismo era una clara respuesta a esa necesidad.

El feminismo vinculado al campo de la izquierda en sus primeros pasos argumentó y defendió el discurso democrático de la época que resignificó la democracia como régimen ideal para una política de construcción colectiva. En esta etapa no se consideró a las estructuras partidarias y los mecanismos eleccionarios como instancias patriarcales, respecto a lo que nada se podía hacer, ni se pensó que la democracia era una "farsa", como sucedia en gran parte de los planteos del feminismo de la segunda ola, fundamentalmente en Estados Unidos.

En tonos distintos se tomó distancia de las posturas exclusivistas

3. Mercedes Sayagués, Aquí, 7 de marzo de 1984, p. 14. 
con respecto a los partidos y a los compañeros, fundamentalmente de aquellas asociadas al feminismo radical. La apuesta al diálogo implicó el despliegue de un discurso no combativo de un "feminismo menos estridente", un feminismo cooperador. Las altas expectativas en la nueva política fueron elementos centrales para configurar una praxis feminista cercana a los imaginarios y prácticas de la izquierda uruguaya.

La estrategia feminista cooperadora no siempre dio buenos resultados, sobre todo por el esfuerzo afectivo e intelectual que implicó realizar el "entrismo feminista", como decían algunas, en la izquierda. Con los años también aumentó la frustración con la democracia, con las expectativas de cambio y con los espacios de la política tradicional. Entonces, fue cada vez más recurrente el llamado al grupo chico y a contestar algunas prácticas políticas que las feministas también habian reproducido y que en el epílogo de la década comenzaron a repensar.

\section{Invierno y repliegue}

Hacia fines de la década del 80 comenzó a delinearse una nueva etapa política para el feminismo de izquierda en Uruguay. Una etapa que se inició con sentimientos de cansancio, hartazgo y desilusión con la izquierda partidaria y con la democracia. Una etapa de enfriamiento y repliegue junto con la reconfiguración de las prácticas políticas feministas de acuerdo al primer contexto desmovilizador de los 90 y de algunas nuevas expectativas generadas con respecto a la posibilidad del triunfo electoral del Frente Amplio hacia los 2000.

En 1989, a pesar de la gran movilización de lo que se conoce como la campaña del "voto verde" liderada por tres mujeres referentes del movimiento de derechos humanos, Uruguay no logró derogar la Ley de Caducidad que impedía juzgar a los responsables del terrorismo de Estado y este tal vez sea el evento que condensa e inaugura la desilusión que experimenta la izquierda de los 90 a los que se suman la caída del Muro de Berlín, la derrota de Nicaragua, la ruptura del Frente Amplio, la crisis del Partido Comunista y el ascenso del Partido Nacional al gobierno con una propuesta neoliberal. ${ }^{4}$

En paralelo a estos grandes eventos, en filas feministas, los "resi-

4. En lo que respecta a la crisis del FA, en 1989 se produce una escisión de los sectores más moderados de la coalición en un contexto en donde la moderación parecía el único camino posible para el triunfo electoral. Este hecho significó un golpe simbólico para una fuerza política que habia hecho de la unidad una de sus principales fortalezas. La crisis del Partido Comunista a principios de los 90 fue otro hecho político que afectó al FA, una crisis desatada por los efectos de la crisis del PCUS y de la renovación a nivel local, cuyo puntapié inicial fue la revisión del concepto "dictadura del proletariado". Hacia 1992 un partido que ostentaba un caudal 
duos de insatisfacción" (Costa, 1988) crecieron de forma constante. La democracia no había traído tantas oportunidades de discusión de nuevas agendas, sino más bien la restauración de viejos liderazgos y formas de hacer política tradicional. En distintos ámbitos, el término "restauración" daba cuenta de que la promesa sobre la nueva política no se había cumplido (Remedi, 2016, p. 174). Los nuevos actores del momento discutían de forma constante cuánto era necesario "transar, negociar y adaptarse al sistema" (Sempol, 2014, p.137).

Si la democracia había incumplido promesas, los actores protagónicos de este proceso, en el caso uruguayo, sin duda habian sido los partidos politicos, incapaces de brindar mayores oportunidades de participación política a las mujeres. La tan ansiada democracia había retornado, pero ni una mujer habia ingresado al Parlamento en 1985. Para las siguientes elecciones de 1989 la preocupación continuaba siendo la misma por parte de las feministas que no habian podido observar ningún avance en materia de representación o discusión sustantiva y constataban en los espacios partidarios la "reproducción de lógicas patriarcales". 5

La decepción con los partidos políticos fue fundamentalmente con la izquierda, con aquel espacio al que se le habian destinado tantas energias y parecía comportarse de forma similar a los partidos "reformistas". Para fines de los 80 la denuncia del autoritarismo se expandió hacia la propia izquierda, una izquierda autoritaria, con "esquemas", con "cocinas", con "autoritarismos", como señala el documento de las feministas del PCU, dominada por lo que llamaban una "ideología masculina". ${ }^{6}$

En el contexto de esta desafección, comenzó a surgir un enojo específico con las estructuras y los compañeros. Aquel discurso que señalaba que sólo la izquierda podría alojar las ideas feministas y que se debía apostar al diálogo constante fue suspendido y se dio paso a la denuncia de la exclusión, las lógicas patriarcales, el machismo de los compañeros, la doble moral y los discursos oportunistas en torno a la cuestión de la mujer sin mayores transformaciones. El nuevo hombre nuevo no era más que una utopía y el machismo, una realidad que alcanzaba a todos y que igualaba a los hombres en una condición antes dificilmente imaginada y menos enunciada. En Cotidiano, en 1989, Lupe Dos Santos señaló el cansancio respecto a "los hombres que luchan a brazo partido

de 500.000 militantes quedó reducido a una mínima expresión de 5.000 y en medio de una crisis financiera, político y afectiva. Ver Lanza (2013).

5. La Cacerola, año 5, no 8, diciembre de 1988, p. 3.

6. "Al fin todos estamos hablando de política", s/f, firmado por Silvia Rodríguez Villamil, Alma Espino, Graciela Duffau, Nadia Delgado, Victoria Szchumacher, Celia Ruiz. 
contra la injusticia y en sus casas reproducen los roles burgueses más recalcitrantes que combaten". ${ }^{7}$

A principios de los 90 habian tomado distancia de Cotidiano varias feministas, y lo mismo había sucedido en Grecmu. Algunas comisiones de mujeres dentro de los partidos se desintegraron, como ocurrió con la Comisión de Mujeres del PCU y la del PVP, o dejaron de funcionar por falta de integrantes, como la Comisión de Mujeres del Frente Amplio y la Comisión de Mujeres del PIT-CNT. De estas comisiones centrales para el feminismo de izquierda, en ningún caso se puede identificar una fecha concreta que date su desintegración, así como tampoco fue noticia o registrado en ningún ámbito el alejamiento de sus integrantes.

Si bien el impacto más importante en el alejamiento lo tuvieron los espacios partidarios y sindicales, esto también afectó a las organizaciones sociales feministas, ya que las dobles militantes no sólo se alejaron de los espacios partidarios sino también de los sociales. Se fue procesando un repliegue que implicó un alto grado de desmovilización y el ingreso a una etapa de invisibilidad del feminismo durante los 90.

Mientras el Partido Nacional gobernaba durante los 90 y siendo constante la impermeabilidad de la izquierda al feminismo, la estrategia "de masas" quedó en suspenso o al menos no fue priorizada. Un buen número de aquellas feministas que integraban el enjambre de abejas que colocaba al feminismo de forma simultánea en varios ámbitos se replegó en su militancia y otras pocas destinaron energías a incidir a nivel gubernamental en algunos espacios donde se renovaron expectativas. Este fue el caso de la intendencia de Montevideo, en donde el Frente Amplio triunfó en 1989 y hacia donde algunas redireccionaron las energías para incidir a nivel de las políticas del gobierno local (Johnson, 2000).

Al impulso de aquellas que habian permanecido dentro del Frente Amplio, como Margarita Percovich, y de quienes aunque no integraban la orgánica del FA igualmente tenían vínculos y buscaron incidir, en el gobierno capitalino se creó la Comisión de la Mujer. Desde esta instancia se generaron iniciativas que permitieron la participación en ciertas áreas, sobre todo a partir de la figura de la experta en ciertos asuntos. La agenda feminista se fue compartimentando y la militancia feminista se fue transformando en un activismo especializado en torno a ciertas temáticas (Johnson, 2000), como violencia, aborto y participación política.

Las feministas continuaron asistiendo a los Encuentros Feministas Latinoamericanos y del Caribe (EFLAC), pero al mismo tiempo dedicaron energias a las conferencias internacionales, incorporaron "el lenguaje de Ginebra" para ejercer presión y luego replicarla en los Estados sobre los acuerdos logrados (Grauer, 2020, pp.110,158). Como señala Sapriza

7. Cotidiano, año II, nº 31 , marzo de 1989, p. 7. 
(2015, p. 951), fueron años dedicados a monitorear a los Estados, a desarrollar nuevas herramientas para la presión política, la negociación y el cabildeo.

Al interior del Frente Amplio, a mediados de la década del 90 se creó la Unidad Temática por los Derechos de las Ciudadanas, cuyo nombre da cuenta de la perspectiva desde la que era abordada la construcción social de la diferencia sexual. El enfoque central fue así el de una democracia debilitada, quedando relegado aquel discurso que denunciaba un sistema desigual en términos socioeconómicos y un orden de género funcional a él. Aquellas pocas que integraron esta unidad durante casi dos décadas completas destinaron energias a fortalecer mujeres en las bases en un contexto de una organización que desconocía el rezago, se negaba sistemáticamente a aplicar el mecanismo de la cuota para mejorar la representación de las mujeres e impulsaba mujeres claramente alejadas del movimiento feminista.

El Frente Amplio llegó al gobierno en 2005 con un amplio respaldo ciudadano de $51,67 \%$ de los votos. En el discurso de asunción de Tabaré Vázquez, el novel presidente comenzó su alocución invocando a los "uruguayos y uruguayas", una frase que para el momento fue extremadamente conmovedora y auspiciante ya que nombraba a quienes suelen quedar invisibilizadas en el discurso universal de la ciudadanía. Si hay un asunto central para el feminismo en estos primeros años de gobierno del Frente Amplio es el del aborto, tanto por las expectativas como por las decepciones que generaron las dificultades de su aprobación.

Durante doce años, ${ }^{8}$ las feministas en las organizaciones sociales y aquellas pocas que resistian en la interna partidaria desplegaron diversas estrategias para que la interrupción del embarazo fuera legal o no fuera penalizada. Las mayorias legislativas que disponía el Frente Amplio tanto en el primer gobierno de Tabaré Vázquez como en el segundo de José Mujica resultaron insuficientes para políticas de la "nueva agenda de derechos" que se consideraron siempre secundarias.

Como señala Verónica Pérez (2019), el movimiento feminista no lograba movilizar grandes contingentes ni desplegar grandes acciones de protesta, por lo que su estrategia fue la de una "politicas de alianza" y un intenso lobby. Una Coordinadora Nacional, denominada primero "por la Defensa de Salud Reproductiva" y luego "por el Aborto Legal", se integró con otras organizaciones como la Universidad de la República, la central sindical y los movimientos de derechos humanos, afrodes-

8. Alcanzar la aprobación de esta norma llevó en total 27 años en Uruguay, dado que el primer proyecto se presentó en 1985, pero fue a partir del 2002 que por primera vez los proyectos pasaron a ser discutidos en las cámaras legislativas 
cendientes, juveniles y LGBT, para aunar esfuerzos (Johnson, Rocha y Schenck, 2015; Pousadela, 2016).

Esto también fue posible gracias a una moderación del discurso feminista, cuyo punto clave fue la Conferencia de El Cairo, desde la que comenzó a plantearse el aborto legal como parte de la salud reproductiva de la mujer y los derechos reproductivos como derechos humanos básicos. A partir de allí, el aborto fue planteado como una demanda ciudadana y no como un reclamo únicamente feminista. Sin embargo, varios proyectos entre 2002 y 2011 fueron presentados y dejaron en evidencia la obstinación de las feministas y la falta de certezas del frenteamplismo que libraba el voto "a la conciencia", y no a la disciplina partidaria como suele pasar con este partido. ${ }^{9}$

Finalmente el aborto en Uruguay fue aprobado en 2012, pero dos hechos históricos quedan en el archivo feminista de la desilusión: el presidente Tabaré Vázquez interpuso un veto parcial sobre los artículos que habilitaban la despenalización del aborto en uno de los momentos más autoritarios del gobierno progresista, y el Frente Amplio, teniendo la mayoría absoluta en ambas cámaras, no aprobó el proyecto por sí mismo y realizó concesiones que muy lejos estaban de la agenda feminista.

En 2013 se aprobó también el matrimonio igualitario. Al igual que lo sucedido con la aprobación de la interrupción voluntaria del embarazo, el matrimonio igualitario fue una demanda enmarcada en un lenguaje de derechos que permitió considerar la universalidad de las propuestas y un asunto de ciudadanía. En este caso las resistencias a la interna de la fuerza política fueron un poco menores respecto a la discusión sobre la interrupción voluntaria del embarazo, aunque igualmente no se contó con un apoyo público por parte de los principales integrantes de la elite gobernante y algunas figuras importantes como José Mujica o Eleuterio Fernández Huidobro expresaron más de una vez su menosprecio a esta causa politica o directamente su homofobia.

En 2017 se modificaron artículos del Código Penal que introdujeron la figura del femicidio como agravante del homicidio y la Ley Integral de Violencia basada en género. Finalmente en 2018, un año antes del ingreso al período de campaña electoral se aprobó la Ley Integral para personas Trans. Las últimas leyes se dieron en un contexto distinto, como fue el de un gran crecimiento del movimiento feminista y de la diversidad sexual, y del estrechamiento del campo de posibilidades para su aprobación en el marco del crecimiento de la reacción conservadora y posible salida del Frente Amplio del gobierno.

Las politicas aprobadas se concretaron durante los gobiernos pro-

9. Sobre el largo proceso de discusión parlamentaria de los proyectos sobre el aborto en Uruguay ver Pérez (2019), Johnson, Rocha y Schenck (2015). 
gresistas y fueron el resultado de un trabajo desde el movimiento social que amplió su política de alianzas en el campo social, contó con algunas aliadas clave dentro del recinto legislativo (Sempol, 2014) y moderó su discurso administrando con discreción la denuncia de un orden de género heteropatriarcal. Las resistencias del Frente Amplio, por su parte, parecen haber significado un incentivo para trabajar por la impugnación del orden de género fuera de la fuerza política o desde otras prácticas.

\section{Primavera feminista}

La nueva agenda de derechos del progresismo convivió y fue superada por movimientos sociales que pusieron en la calle los temas de agenda, que hicieron posible su visibilización, que generaron condiciones de escucha desde la elite gobernante y al mismo tiempo permitieron discutir los límites del Estado como único responsable de los cambios sociales. Desde principios del siglo XXI la calle fue tomada en fechas concretas por parte de integrantes del movimiento feminista y gay-lésbico, mostrando una capacidad de movilización que superó a la capacidad de movilización de la izquierda.

La Marcha de la Diversidad, denominación que adquirió lo que previamente había sido la Marcha del Orgullo Gay, continuó siendo una fiesta pero también se erigió como un espacio de confluencia de quienes buscaban alterar el orden establecido o frenar las iniciativas conservadoras. En 2014 la Coordinadora de la Marcha de la Diversidad decidió incorporar en su consigna el rechazo a la baja de la edad de imputabilidad penal que se plebiscitaba junto a las elecciones generales. Esto fue un hito que mostraba la importancia política de este movimiento y la capitalización política que de él se podía realizar.

El feminismo también volvió a la calle, al principio con un contingente de mujeres muy escaso, pero que igualmente marca el inicio de un nuevo ciclo de protesta feminista. La discusión sobre el aborto fue un momento clave para el despliegue en el espacio público de una intervención que buscaba expresar su descontento. La campaña de la mano que vota fue un primer indicio. Una estrategia de protesta comportada, que no utilizaba ninguna parte sexualizada del cuerpo, sino una mano de cartón que votaba una ley que los parlamentarios no querian votar, pero también un dispositivo muy efectivo para hacer visible al feminismo durante la discusión (Vacareza, 2020, p. 44).

La mano que vota se hizo presente en varias instancias, desde las gradas de las cámaras durante la discusión hasta diversos espacios públicos; entre los más significativos cabe señalar el domicilio de Tabaré Vázquez, en torno al cual se llevó una mano gigante un 8 de marzo del 2006 ante las declaraciones amenazantes sobre su voluntad de vetar 
la ley en caso de aprobarse y otros "amaneceres naranjas", durante la discusión del nuevo proyecto en 2012. Estas fueron instancias puntuales pero que hicieron visible al feminismo en la calle y que además acercaron a una nueva generación de jóvenes feministas acumulando indignación particularmente con el Frente Amplio.

Durante la discusión en Diputados, un mes antes de que se aprobara finalmente el proyecto, Mujer y Salud en Uruguay (MYSU), una de las organizaciones feministas protagonistas de este debate, realizó una intervención en las afueras del Palacio Legislativo, en la que se hicieron presentes mujeres desnudas con sus cuerpos pintados de naranja bajo la consigna "Ellos ponen las condiciones, nosotras ponemos el cuerpo". Tal vez esta acción representa el momento más álgido de la protesta feminista en las dos décadas que transcurren entre los 90 y los dos mil. Una instancia de resurgir irreverente feminista que, rodeando a un tema específico, se cierra con la promulgación de la ley, pero que siendo una victoria más que agridulce lega a otras generaciones la sospecha cada vez más creciente sobre los limites del frenteamplismo y una praxis feminista hacia los partidos y el Estado.

Mientras el Frente Amplio gobernaba, fueron surgiendo un repertorio de nuevas organizaciones sociales preocupadas por la desigualdad social en su más amplio sentido. Organizaciones que impugnaban el disciplinamiento heterosexual y denunciaban la violencia hacia las disidencias sexuales y de género, organizaciones de mujeres afrodescendientes que emergieron denunciando el patriarcado y el racismo y nuevas organizaciones feministas que en su gran mayoría además de antipatriarcales $\mathrm{y}$ antirracistas se definieron anticapitalistas.

En su mayoría estas nuevas organizaciones fueron fundadas por mujeres muy jóvenes, entre los 20 y 30 años, con experiencia militante en otros movimientos, fundamentalmente en el movimiento estudiantil y cuyas primeras preocupaciones feministas emergieron con la campaña por el aborto y fueron reforzadas en el contacto de los feminismos de la región, particularmente por la asistencia a los Encuentros Nacionales de Mujeres en Argentina (Grabino y Menéndez, 2014). Se trataba de organizaciones que se autoproclamaban autónomas y convocaron a tener una praxis feminista propia, fuera de los códigos de la politica tradicional. Escribieron y apostaron a construir una nueva práctica del "entre-mujeres" que impugna la "mediación patriarcal" (Gutiérrez, Sosa y Reyes , 2018).

A diferencia de las feministas de los 80 , la práctica de la autoconciencia se transformó en una referencia de los nuevos modos del devenir feminista y una búsqueda de ir a la raíz de los problemas. Lo que en los 80 había sido una consigna poco traducida a las prácticas (De Giorgi, 2020), la idea de "lo personal es político", emergió como un nuevo sím- 
bolo para quienes reivindicaron y reivindican politizar la experiencia personal. La dinámica del pequeño grupo se transformó en un modo de la praxis feminista de esta nueva etapa, en la que unas pocas jóvenes feministas politizan sus experiencias personales y crean sus propios espacios de formación tomando clara distancia del saber experto "de género" y de los espacios académicos (Gargallo, 2019).

Estas iniciativas se desplegaron en el marco de una crítica a las instituciones y a los espacios mixtos, y fundamentalmente a organizaciones feministas orientadas a la incidencia en el Estado. Textos como el de Silvia Federici (2014), sobre la discusión de los 90 en torno al feminismo y su relación con los organismos internacionales a propósito de la Conferencia de Beijing, fueron referenciados de forma recurrente y trajeron al escenario uruguayo un debate sobre la autonomía del movimiento feminista con una fuerza que no había tenido en el momento de su surgimiento, como había sucedido en otros países latinoamericanos.

A partir de 2015 ese movimiento feminista "por abajo" que se venía gestando se hizo visible en las movilizaciones callejeras, impulsadas por la marcha Ni una Menos en Argentina. Las movilizaciones del 8 de marzo en los años 2016, 2017, 2018, 2019 y 2020 fueron cada vez más masivas y expresaron un resurgir del movimiento feminista que volvió a la calle y además buscó intervenir el espacio público desde otras prácticas. En los últimos años, los 8 de marzo fueron sin estrado, sin micrófono, con fogata en el medio de la avenida principal, con performances e intervenciones artísticas que claramente tomaban distancia de los modos tradicionales de ocupar la calle y con una constante discusión sobre si marchar o no con "los compañeros".

El feminismo cooperador de aquella transición democrática se reconfiguró a partir de nuevas organizaciones que proponian "cambiarlo todo". Impugnaciones a la política formal, a los buenos modales democráticos construyeron un repertorio de protestas feministas dentro del feminismo que provocaron sin dudas conflictos, pero también ampliaron la polifonía y sobre todo los márgenes para la irreverencia. Aquella consigna de los 80, "democracia en la casa y en la cama", retornó con un ímpetu más disruptivo para gritar ahora "revolución en la casa y en la cama".

Una radicalidad feminista se hizo el lugar que antes no había podido o querido alcanzar, tal vez, porque se terminó aquel mandato de ser dignas y decentes para obtener el reconocimiento progresista (Garga1lo, 2014, p.54) o porque la "patrulla ideológica de la izquierda" (Costa, 1988) sobre el feminismo perdió aquel efecto amenazante de antaño. El término "autonomía" se hizo cada vez más protagonista y fue utilizado de forma recurrente para dar cuenta de espacios y encuentros feministas que tomaban clara distancia con el mundo sindical y partidario, particularmente con la izquierda frenteamplista. 
Se realizaron encuentros de mujeres emulando los encuentros argentinos, emergieron nuevas organizaciones y se constituyó una red de organizaciones denominada Coordinadora de Feminismos que nucleó a organizaciones de mujeres que no priorizaba la estrategia de lobby hacia el Estado ni la incidencia en las políticas públicas. Los últimos años fueron tiempos de irreverencia, de renovación de votos con la utopía y de marcar el momento político como un "tiempo de rebelión" (Minervas, 2019).

Cabe señalar además que esta autonomía, con respecto a la izquierda partidaria, no implicó un alejamiento de la preocupación por la desigualdad de clase, sino lo contrario, ya que se transitó por una complejización de la lectura sobre la opresión de género y se expandió una mirada anticapitalista. Una nueva biblioteca feminista acompañó este proceso con los textos de Silvia Frederici como referente principal y otras latinoamericanas que focalizan la atención en el trabajo asalariado y la propiedad privada como mecanismo destructor de los lazos comunales y la implantación del orden de género (Gutiérrez Aguilar, Salazar y Tzul, 2016; Lugones, 2014; Tzul Tzul, 2018).

La propuesta de "parar el mundo" con el Paro Internacional de Mujeres o la de poner "la vida en el centro" se erigió como una propuesta feminista anticapitalista que buscaba restarle energías a la lógica del capital. En este sentido, una izquierda feminista creció y se expandió fuera del Frente Amplio, caducando así aquella amenaza de los 80 sobre la autonomía feminista y su deriva pequeñoburguesa. El término "feminismo popular" comenzó a circular mucho más en estos espacios autónomos que en los frenteamplistas.

Este tono irreverente y el despliegue de una praxis feminista por fuera de la izquierda partidaria y sindical son una marca identitaria de esta primavera feminista, pero no la única ya que luego también surgieron nuevas organizaciones y grupos feministas dentro de las estructuras tradicionales. Esto sucedió ante el influjo del movimiento general que interpeló a varias mujeres en distintos espacios y luego al crecimiento de la reacción conservadora que amenazó y amenaza con frenar y desarmar los dispositivos de la nueva agenda de derechos.

Las nuevas generaciones de feministas frenteamplistas se iniciaron en la desilusión, o la vergüenza, del veto de Tabaré Vázquez, pero también en un contexto feminista que les trasmitió la suficiente confianza como para hacer de ello un motivo para permanecer y luchar, dentro de limites muy estrechos, intentando ampliar los márgenes de tolerancia del frenteamplismo hacia el feminismo. En los últimos años se realizaron nuevos encuentros de mujeres frenteamplistas, se creó La Comité, un espacio orgánico declarado feminista y algunas nuevas feministas se incorporaron a sectores políticos que integran el partido. Todo ello 
sucedió al influjo del movimiento feminista, más que a cambios producidos internos.

Las transformaciones feministas dentro de la izquierda partidaria parecen haber ocurrido fundamentalmente dentro de los espacios gubernamentales cuando el FA era gobierno y desde una institución nueva, el Ministerio de Desarrollo Social (MIDES), cuya principal misión fue la de administrar y revertir la desigualdad social. Un nuevo espacio de construcción política y de "vuelta al terreno" en un proceso que integró a un gran contingente de jóvenes feministas, militantes por la diversidad sexual y antirracistas que ampliaron los sentidos de la desigualdad mientras la estudiaban y la intervenían, y mientras toleraban a los propios compañeros de la fuerza política que no consideraban aquella agenda dentro de las prioridades de la izquierda.

Las pocas que habitan el feminismo frenteamplista, aunque tienen muchísimo vínculo con el movimiento social, no tienen doble militancia, como sucedía en los 80 . Resisten siendo feministas y frenteamplistas entre mujeres, se arman su pequeño grupo, desde el que predican y buscan desplegar otras prácticas políticas, que las llaman "más amorosas". No les gustan los grupos "solo de mujeres", en los que "se aburren", pero gestionan igualmente un grupo pequeño de sostenimiento emocional, es decir que se milita con varones y se conversa entre mujeres (feministas). Aunque no hay referencias autorales al "entre-mujeres", su práctica de resistencia en los espacios patriarcales se parece bastante a aquella desplegada en los grupos autónomos.

Su espacio social de referencia suele ser un nuevo ámbito de coordinación que surgió en 2017 como es la Intersocial Feminista. Esta es una propuesta que, a diferencia de la Coordinadora, propone y legitima la praxis feminista hacia los espacios mixtos, es decir compuestos por varones, y realiza una estrategia de coordinación y demandas hacia el Estado, particularmente en lo que refiere a las políticas contra la violencia hacia las mujeres. La Intersocial afecta e interpela particularmente a la central sindical, que no sin dificultades incorporó en su discurso y en su orgánica planteos feministas, como sucedió claramente el 1 de mayo del 2021.

El desafio para el feminismo frenteamplista es el de hacer realidad la declaración de "antipatriarcal" aprobada en el congreso partidario. Una declaración que no se ha traducido en ninguna medida concreta, pero que oficia como plataforma discursiva para demandar la paridad en los cargos políticos. Así la disputa por los espacios de poder y por lograr una participación igualitaria en términos de representación absorbe todas las energías de las feministas frenteamplistas y obtura las posibilidades de ampliar la discusión feminista hacia otro registro más estructural que permita discutir el orden de género en su complejidad toda. 


\section{Apuntes finales}

El "matrimonio infeliz", el "amor no correspondido", las incompatibilidades y los desamores entre el feminismo y la izquierda son una parte muy importante de la historia del feminismo en Uruguay, al menos desde la posdictadura hasta la actualidad. Lo primero a destacar de esta tensión es la búsqueda del encuentro en su primera etapa, ese esfuerzo político y afectivo que un importante grupo de feministas realizaron en los 80 al calor de las nuevas expectativas por la renovación de la izquierda. Aunque este esfuerzo no arrojó los resultados esperados, permitió la emergencia de un feminismo de izquierda que se nutrió de las ideas y prácticas de esta última. Esto implicó el despliegue de un feminismo que hizo centro en la preocupación por la desigualdad de clase, pero que al mismo tiempo moderó su irreverencia frente al patriarcado.

Herederas de una cultura de izquierda que les había permitido emanciparse de su horizonte doméstico, las feministas desplegaron una praxis dentro de los marcos de la cultura de izquierda. A pesar de toda la estrategia cooperadora hacia el Estado y los partidos, el feminismo de izquierda fue muy poco escuchado. Los 80 finalizaron con un amplio repertorio de desilusiones a diversa escala, pero una de ellas fue la de la constatación de la poca tolerancia feminista de la izquierda partidaria.

Aquellas feministas que continuaron militando fueron pocas y lo hicieron fuera de la izquierda partidaria y bajo una nueva estrategia, enfocada en la demanda de políticas hacia temas concretos. Para ello elaboraron un discurso anclado en los derechos, y no tanto en la denuncia de un sistema opresor, y aprendieron a tejer alianzas en un contexto político más que inhóspito, no sólo de los 90 neoliberales, sino de una izquierda que había virado hacia el centro y no tomaba riesgos en aras de llegar al gobierno.

Fue durante los gobiernos del progresismo que se concretó lo que se conoce como "nueva agenda de derechos", un repertorio de políticas cuyo público principal fueron las mujeres y las disidencias sexuales. La nueva agenda de derechos se transformó en un símbolo de la era progresista, pero fue un resultado de la presión del movimiento social y de algunas aliadas frenteamplistas que, obstinadas, resistían en la intemperie. En esos años, las calles comenzaron a inundarse de furia y fiesta, entre la Marcha de la Diversidad y el 8 de Marzo, mientras la izquierda partidaria perdía abruptamente su capacidad de movilización y de ser un referente para la utopía del cambio social.

No cabe duda de que los avances en materia de políticas públicas que intervienen sobre el orden de género se realizaron durante los quince años de gobierno frenteamplista, pero al mismo tiempo la izquierda partidaria demostró los límites que ofrecía para promover un cambio 
cultural profundo y alterar sus prácticas políticas. Las nuevas generaciones de militantes feministas entonces encuentran poco atractivo aquel espacio que ni siquiera se ha atrevido a postular una candidata mujer a la presidencia.

Si en el primer ciclo feminista las feministas marxistas integraban y militaban todas adentro del Frente Amplio, en este último ciclo eso dejó de suceder. Un repertorio amplio de organizaciones se enuncia como anticapitalistas y antirracistas denunciando un sistema de opresión racista y heteropatriarcal mientras el frenteamplismo ocupa simbólicamente el lugar del reformismo. Todavía se renuevan energías en aquellas que intentan educar a los compañeros al interior del FA, pero la izquierda partidaria es una maquinaria expulsora de rebeldias feministas. Esta nueva primavera feminista es mucho más calurosa y revoltosa que su antecesora, y por tanto deja planteada la interrogante de si habrá o no repliegue a un nuevo invierno.

\section{Referencias}

Costa, A. (1988). E viável o feminismo nos trópicos? Resíduos de insatisfação. São paulo, 1970, Cadernos de Pesquisa, 66, 63-69.

De Giorgi, A.L. (2020). Historia de un amor no correspondido. Feminismo e izquierda en los ochenta. Sujetos Editores.

Federici, S. (2014). Rumbo a Beijing ¿Cómo las Naciones Unidas colonizaron el movimiento feminista? Revista Contrapunto, 87-96.

Feliú, V. (2009). ¿Es el chile de la post-dictadura feminista? Estudos Feministas, 17 (3), 701-715.

Garcé, A. y J. Yaffé (2005). La era progresista. Fin de Siglo.

Gargallo, F. (2014). Feminismos desde Abya Yala. Ideas y proposiciones de las mujeres de 607 pueblos en nuestra América. Universidad Autónoma de la Ciudad de México (UACM).

Gargallo, F. (2019). Reflexiones en torno a ideas y prácticas del entre-mujeres a principios del siglo XXI. Librería La Cosecha.

Grabino, V. y M. Menéndez (2014). Como cuentas de collar. Colectivos de mujeres y feminismos en Uruguay. Contrapunto, 5, 23-45.

Grammático, K. (2005). Las mujeres politicas y las feministas en los tempranos setenta: ¿Un diálogo (im)posible? En A. Andújar et al. (comps.), Historia, género y politica en los 70. Feminaria Editora, pp. 19-38.

Grauer, D. (2020). De la clase a los derechos. Movimiento feminista y Frente Amplio, disputas y transformaciones en la izquierda en Uruguay, 19842004. Tesis de maestría. Universidad de la República.

Gutiérrez, R., N. Sosa e I. Reyes (2018). El entre mujeres como negación de las formas de interdependencia impuestas por el patriarcado capitalista y colonial. Reflexiones en torno a la violencia y la mediación patriarcal, Revista Heterotopias, 1, 1, 1-15. 
Gutiérrez Aguilar, R., H. Salazar y G. Tzul (2016). Leer el siglo XX a contrapelo. Constelaciones de historias comunitarias de luchas por territorios y autogobierno en Bolivia y Guatemala. El Apantle. Revista de Estudios Comunitarios, 2, 61-100.

Johnson, N. (2000). The right to have rights: gender politics, citizenship and the state in Uruguay. Tesis doctoral. Queen Mary and Westfield College, University of London.

Johnson, N., C. Rocha y M. Schenck (2015). La inserción del aborto en la agenda político-pública uruguaya, 1985-2013. Un análisis desde el Movimiento Feminista. Cotidiano Mujer.

Kirkwood, J. (1983). El feminismo como negación del autoritarismo. Material de discusión FLACSO, $\mathrm{n}^{\circ} 52$, Santiago de Chile.

Kirkwood, J. (1984). Feministas y politicas. Material de discusión FLACSO, $\mathrm{n}^{\circ}$ 63, Santiago de Chile.

Lanza, F. (2013). La crisis del partido comunista uruguayo (1989-1992). Tesis de Maestría. Universidad de la República, Uruguay.

Lesgart, C. (2003). Usos de la transición a la democracia. Ensayo, ciencia y política en la década del 80. Homo Sapiens.

Lugones M. (2014). Colonialidad y género. En Y. Espinosa, D. Gómez, y K. Ochoa, Tejiendo de otro modo: Feminismo, epistemología y apuestas descoloniales en Abya Yala. Universidad del Cauca-Popayán.

Minervas (2019). Momento de paro. Tiempo de rebelión. Miradas feministas para reinventar la lucha. Minerva Colectivo de Mujeres.

Olea, C. (comp.) (1998). Encuentros, (des)encuentros y búsquedas. El movimiento feminista de América Latina. Flora Tristán.

Pedro, J. (2010). Narrativas do feminismo em países do Cone Sul (19601989). En J. Pedro y C. Wolff, Gênero, feminismos e ditaduras no Cone Sul, pp. 115-137. Editora Mulheres.

Pérez V. (2019). La politica del aborto legal en América Latina. Tesis doctoral. Universidad Torcuato Di Tella, Argentina.

Pieper, J. (2010). Forging feminisms under dictatorship: women's international ties and national feminist empowerment in Chile, 1973-1990. Women's History Review, 19 (4), 613-630.

Pousadela, I. (2016). Nadie más se calla. El movimiento de mujeres y el proceso de ampliación de la ciudadanía en Uruguay, 1985-2015. Encuentros, 9 (1), 71-94.

Remedi, G. (2016). Transiciones/traslaciones: recorrido personal y ensayo retrospectivo de los estudios literarios en los 80. En C. Demasi y A. De Giorgi (comps.), El retorno a la democracia: otras miradas, pp. 169-197. Fin de siglo.

Rico, A. (2005). Cómo nos domina la clase gobernante. Orden politico y obediencia social en la posdictadura. 1985-2005. Trilce.

Richard, N. (2001). La problemática del feminismo en los años de la transición en Chile. En D. Mato (comp.), Estudios latinoamericanos sobre 
cultura y transformaciones sociales en tiempos de globalización, pp 227239. Clacso.

Sapriza, G. (2015). "Nos habíamos amado tanto". Años revueltos, mujeres, colectivos y la pelea por el espacio público. Estudos Feministas, 23 (3), 939-958.

Sempol, D. (2014). Transiciones democráticas, violencia policial y organizaciones homosexuales y lésbicas en Buenos Aires y Montevideo. Tesis doctoral en Ciencias Sociales. Universidad Nacional General Sarmiento, Argentina.

Trebisacce, C. (2010). Una segunda lectura sobre las feministas de los 70 en Argentina. Conflicto Social, 3 (4), 26-52.

Trebisacce, C. (2011). Un análisis de las narrativas construidas por las feministas de ATEM 25 de noviembre, en los 80, sobre el feminismo local precedente. En II Jornadas del Centro Interdisciplinario de Investigaciones en Género, La Plata, Argentina. Disponible en http: / /www.memoria. fahce.unlp.edu.ar/trab_eventos/ev.4898/ev.4898.pdf.

Trebisacce, C. (2013a). Encuentros y desencuentros entre la militancia de izquierda y el feminismo en la Argentina. Estudos Feministas, 21 (2), 439-462.

Trebisacce, C. (2013b). Un fantasma recorre la izquierda nacional. El feminismo de la segunda ola y la lucha política en Argentina en los años setenta, Sociedad y Economía, 24, 95-120.

Tzul Tzul, G. (2018). Sistemas de gobierno comunal indígena: la organización de la reproducción de la vida. En M. Meneses y K. Bidaseca (eds.), Epistemologias del Sur: Epistemologias do Sul, pp. 385-396. Clacso.

Vacareza, N. (2020). La mano que vota. Visualidad y afectos en un símbolo transnacional del movimiento por el derecho al aborto en el Cono Sur. Sexualidad, Salud y Sociedad, 35, 35-57.

Viano, C. (2014). Voces (des-encontradas) en los Encuentros Nacionales de Mujeres en Argentina. Revista Digital de la Escuela de Historia, 6 (11), 49-68.

Yaffé, J. (2005). Al centro y adentro. La renovación en la izquierda y el triunfo del Frente Amplio en Uruguay. Linardi y Risso. 